\title{
Biosurveillance of selected pathogens with zoonotic potential in a zoological collection
}

\author{
Pavel Kvapil ${ }^{1}$, Jožko Račnik ${ }^{2}$, Marjan Kastelic ${ }^{3}$, Jiřina Markováa ${ }^{4}$, Jean Murat ${ }^{5}$, Monika \\ Kobédová $^{6}$, Pavlina Pittermanová ${ }^{6}$, Marie Budíkováa ${ }^{7}$ Kamil Sedlák ${ }^{8}$, and Eva Bartova ${ }^{6}$ \\ ${ }^{1}$ ZOO Ljubljana \\ ${ }^{2}$ University of Ljubljana Faculty of Veterinary Medicine \\ ${ }^{3}$ ZOO Ljubljana \\ ${ }^{4}$ University of Veterinary and Pharmaceutical Sciences Brno Faculty of Veterinary Hygiene \\ and Ecology \\ ${ }^{5}$ University of Limoges Medical Faculty \\ ${ }^{6}$ University of Veterinary and Pharmaceutical Sciences Brno Department of Biology and \\ Wildlife Diseases \\ ${ }^{7}$ Masaryk University Faculty of Science \\ ${ }^{8}$ State Veterinary Institute Prague
}

January 25, 2021

\begin{abstract}
Monitoring infectious diseases is one of the most important pillars of preventive medicine in zoological collections. Screening for parasitic and bacterial infections is obligatory for keeping animals and equipment safe from pathogens that may pose a risk to animal and human health. Zoological collections usually contain many different animal species, living in close proximity with people and wild animals. As an epidemiological probe, 188 animals (122 mammals, 65 birds, and one reptile) from a zoo in Slovenia were examined for selected pathogens. Antibodies to Toxoplasma gondii and Neospora caninum were detected by ELISA in $37 \%$ and $3 \%$ of mammals, and in $0 \%$ and $3 \%$ of birds, respectively; the reptile was negative. A statistically significant difference in T. gondii prevalence was found in Carnivora $(78 \%)$ compared to Cetartiodactyla $(33 \%, \mathrm{p}=0.0227)$ and Primates $(25 \%, \mathrm{p}=0.0084)$. Antibodies to Encephalitozoon cuniculi were detected by IFAT in $55 \%$ of mammals and $34 \%$ of birds, respectively; the reptile was negative. Herbivores had a higher chance of being infected with E. cuniculi compared to omnivores $(\mathrm{p}=0.0015)$. Antibodies to Chlamydia abortus and Coxiella burnetii were not detected in any of the zoo animals. The sera of 39 wild rodents found in the zoo were also examined; they were negative for all three parasites. The parasite T. gondii was detected by PCR in the tissue of two mute swans (Cygnus olor), one laboratory mouse, two Mus musculus, one Apodemus flavicollis, and one Apodemus agrarius. Positive samples were genotyped by a single multiplex PCR assay using 15 microsatellite markers; one sample from a mute swan was characterized as type II. This micro-epidemiological study offers a better understanding of pathogens in zoo animals and an understanding the role of zoos in biosurveillance.
\end{abstract}

\section{Introduction}

The role of zoological collections in biosurveillance has been proven in the past (McNamara, 2007). Many different animal species usually live in a small area and in proximity to keepers, visitors, and other wildlife. In some situations, infectious pressure might overcome the immune defense of zoo animals, and pathogens might spread across various animal species. In this context, infectious diseases monitoring is an extremely important part of preventive veterinary medicine in zoological collections. A well-designed vaccination program and regular coprological examinations, including flotation and sedimentation techniques, are obligatory in order 
to provide good health care for animals in the zoo. A detailed screening plan for selected pathogens based on the current epidemiological situation is of imminent importance for the safety of animals and employees, as well as visitors. The possibility of discovering infectious threats such as toxoplasmosis, neosporosis, chlamydiosis, and encephalitozoonosis makes zoos suitable epidemiological stations. The aim of this study was to monitor selected pathogens at the Ljubljana Zoo in Slovenia and examine its role as a sentinel in biosurveillance.

\section{Materials and methods}

The zoo is located on the outskirts of Ljubljana (coordinates 46 $3^{\prime} 9.25^{\prime \prime} \mathrm{N}, 14 \mathrm{deg} 28^{\prime} 20.08^{\prime \prime} \mathrm{E}$ ) and covers an area of 6 hectares with a large collection of exotic mammals, birds, and reptiles. Blood samples were collected from the jugular vein of 123 mammals and 65 birds in 2014 and 2015 (Table 1) and the serum was stored at $-20 \mathrm{oC}$ until assay. Tissue samples (brains or liver) of ten animals that died at the Ljubljana Zoo in 2015 were also examined. These included two mute swans (Cygnus olor), one black stork (Coconia nigra), two brown rats (Rattus norvegicusvar. alba), one fat-tailed gerbil (Pachyuromys duprasi), one alpaca (Vicugna pacos ), two Japanese quail (Coturnix japonica), and one laboratory mouse (Mus musculus var.alba) used as food for zoo animals. As a part of the deratization program at the Ljubljana Zoo, sera from 39 wild rodents $(n=$ $39)$ and brain tissue $(n=11)$ were collected and used for assays. The rodents included 28 eastern house mice (Mus musculus), four brown rats (Rattus norvegicus), four yellow-necked mice (Apodemus flavicollis), two bank voles (Clethrionomys glareolus), and one striped field mouse (Apodemus agrarius ). All the samples used in this study were either blood samples collected during surgeries and preventive annual routines where blood was used for other reasons, or tissues from dead animals and rodents collected during the deratization program.

Enzyme Linked Immuno Sorbent Assay (ELISA) was used to detect antibodies to T. gondii, N. caninum , C. burnetii, and C. abortus with the ELISA kit ID Screen T. gondii Indirect Multi-Species, ID Screen N. caninum Indirect Multi-Species, ID Screen Q Fever Indirect Multi-Species, and ID Screen Chlamydia abortus Indirect Multi-Species, IDvet, Grabels, France, respectively. Samples with S/P (\%) [?] 60\% and $\mathrm{S} / \mathrm{P}(\%)$ [?] $50 \%$ were classified as positive for C. abortus and for the other infections mentioned above, respectively. Antibodies to E. cuniculi were determined by an indirect immunofluorescent antibody test using MegaScreen Fluoencephalitozoon (Megacor Diagnostic, Horbranz, Austria) withE. cuniculi antigen and specific conjugates: anti-bovine, anti-goat, and anti-sheep IgG (VMRD, Pullman, Chicago, USA) for Bovidae, anti-camel IgG (VMRD) for Camelidae, anti-deer IgG (KPL Inc. Gaithersburg, Maryland, USA) for Cervidae, anti-horse IgG (VMRD) for Equidae, anti-cat IgG (Sigma Aldrich, St. Louis, USA) for Felidae and Ursidae, anti-dog IgG (Sigma Aldrich) for Canidae, and anti-pig IgG (Sigma Aldrich) for Suidae. Sera were diluted with phosphate-buffered saline twofold starting with 1:50; samples with a titer [?] 50 were marked as positive.

The DNA was isolated by the QIAamp DNA Mini Kit (Qiagen, Courtaboeuf, France); in the case of $E$. cuniculi , the tissue was first homogenized using a tissue homogenizer. Detection of T. gondiiwas done by PCR amplification of the TGR1E sequence (Cristina, 1991). The PCR mixture contained $3 \mu \mathrm{l}$ of DNA, 20 $\mu \mathrm{l}$ of PPP master mix (Top-Bio s.r.o., Prague, Czech Republic), $0.5 \mu \mathrm{l}$ of each primer $(0.1 \mathrm{mM})$, and $16 \mu l$ of PCR-grade $\mathrm{H}_{2} \mathrm{O}$. PCR was performed at the following conditions: $94{ }^{\circ} \mathrm{C} 5 \mathrm{~min}, 35$ cycles of $94{ }^{\circ} \mathrm{C} 0.5 \mathrm{~min}$, $68{ }^{\circ} \mathrm{C} 40 \mathrm{~s}$, and $72{ }^{\circ} \mathrm{C} 40 \mathrm{~s}$ and $72{ }^{\circ} \mathrm{C} 5 \mathrm{~min}$. Genotyping of T. gondii -positive samples was performed with a single multiplex PCR assay with 15 microsatellite markers (Ajzenberg, 2010). Detection of $N$. caninumwas done with PCR amplification of the Nc-5 region (Muller, 1996). The PCR mixture contained $2 \mu$ l of DNA, $12.5 \mu \mathrm{l}$ of PPP master mix (Top-Bio s.r.o), $0.1 \mu \mathrm{l}$ of each primer $\left(0.1 \mathrm{mM}\right.$ ), and $10.4 \mu \mathrm{l}$ of PCR-grade $\mathrm{H}_{2} \mathrm{O}$. PCR was performed at the following conditions: $94{ }^{\circ} \mathrm{C} 5 \mathrm{~min}, 35$ cycles of $94{ }^{\circ} \mathrm{C} 1 \mathrm{~min}, 63{ }^{\circ} \mathrm{C} 30 \mathrm{~s}$, and 72 ${ }^{\circ} \mathrm{C} 1 \mathrm{~min}$ and $72{ }^{\circ} \mathrm{C} 10 \mathrm{~min}$. Detection of E. cuniculi was done with PCR amplification of a small subunit of rRNA using the primers ECUNF/ECUNR (Valenčáková, 2005). The PCR mixture contained $1 \mu$ l of DNA, $12.5 \mu \mathrm{l}$ of PPP master mix (Top-Bio s.r.o.), $1 \mu \mathrm{l}$ of each primer, and $9.5 \mu \mathrm{l}$ of PCR-grade $\mathrm{H}_{2} \mathrm{O}$. PCR was performed at these conditions: $95{ }^{\circ} \mathrm{C} 3 \mathrm{~min}, 35$ cycles of $95{ }^{\circ} \mathrm{C} 30 \mathrm{~s}, 60{ }^{\circ} \mathrm{C} 30 \mathrm{~s}$, and $72{ }^{\circ} \mathrm{C} 1.5$ min and 72 
${ }^{\circ} \mathrm{C} 10$ min. PCR products were analyzed on $2 \%$ agarose gel. The prevalence was statistically analyzed with Pearson's chi-squared test for independence using STATISTICA Cz 12 (Statsoft, 2013) or with the Monte Carlo method using IBM SPSS Statistics 20. The null hypothesis that seroprevalence in mammals does not differ by orders, families, diet, and sex was tested. The differences were considered statistically significant when the $p$-value was [?] 0.05. In the case of a statistically significant difference, the Scheffe multiple comparison method (Statistica $\mathrm{Cz} 12$ ) was subsequently applied.

\section{Results}

The presence of selected parasites (T. gondii, N. caninum, and E. cuniculi) and bacteria (C. abortus and C. burnetii ) was monitored in zoo animals from Slovenia. Antibodies to T. gondii, N. caninum, and E. cuniculi were detected in $37 \%$ (46/123), $3 \%$ (4/122), and 55\% (52/95) of mammals, respectively, and in $0 \%$ $(0 / 50), 3 \%(1 / 30)$, and $34 \%(11 / 32)$ of birds, respectively (Table 1$)$.

In mammals, the highest prevalence of T. gondii antibodies was found in Carnivora (78\%), including two lynx, one leopard, one tiger, and three brown bears. Higher T. gondii seroprevalence was found in females compared to males and in omnivores compared to carnivores and herbivores, but without the statistical differences $(p>0.05)$. A statistically significant difference of $T$. gondii prevalence was found in Carnivora (95\% CI: $50.6-100 \%)$ compared to Cetartiodactyla $(p=0.0227,95 \%$ CI: $21.7-45 \%)$ and Primates $(p=$ 0.0084, 95\% CI: $38.6-78.1 \%)$. Antibodies to $N$. caninum were detected only in Cetartiodactyla (6\%) without statistical differences $(p>0.05)$ in order, sex, and diet. The highest prevalence of E. cuniculi antibodies was found in Lagomorpha (83\%) and Cetartiodactyla (65\%). There was a statistically significant difference in seroprevalence in Camelidae (66.7\%, 95\% CI: 35.9-97.5\%) compared to Bovidae $(p=0.0243,81.3 \%, 95 \%$ CI: $67.7-94.8 \%)$. Herbivores $(63.2 \%, 95 \%$ CI: $52.3-74 \%)$ had a higher chance of being infected with $E$. cuniculi compared to omnivores $(p=0.0015,13.3 \%, 95 \%$ CI: 0-30.5\%). Mixed infection with T. gondii and N. caninum was found in 1.6\% (2/122) of mammals (two domestic sheep), E. cuniculi and T. gondii in $17 \%$ (16/95) of mammals (three from Carnivora and 13 from Cetartiodactyla), and E. cuniculi and N. caninum in $3 \%$ (3/94) of mammals (from Cetartiodactyla). Two domestic sheep had antibodies to all three parasites. Antibodies to $C$. abortus and $C$. burnetii were not found in any of the animals tested. The results of the serological examination of mammals according to different characteristics are presented in Table 2.

In birds, antibodies to $N$. caninum were found in one animal, in a 14-year-old female blue-and-yellow macaw Ara ararauna, and antibodies to E. cuniculi were found in 34\% (11/32) of animals, in 8- and 15-year-old male mute swans, and in five female and four male helmeted guineafowls (Numida meleagris ) 6 months to 5 years old. There was no mixed infection of $N$. caninum and E. cuniculi . All the birds tested were negative for antibodies to T. gondii $(0 / 50)$ and C. abortus $(0 / 26)$.

Antibodies to T. gondii, N. caninum, E. cuniculi, and C. burnetii were not found in any of the 39 wild rodents; antibodies to C. abortus were not examined.

The parasite T. gondii was found by PCR in the tissue of seven of 21 (33\%) animals, in two mute swans, one laboratory mouse, two eastern house mice, one yellow-necked field mouse, and one striped field mouse. The sample from a mute swan was successfully genotyped and characterized as type II. The parasites $N$. caninum and E. cuniculi were not found by PCR in any of the tissue samples.

\section{Discussion}

The main source of parasitic infection in zoo animals is not well known. At the Ljubljana Zoo, as in other European zoos, feeding carnivores with raw meat that is potentially infected with $T$. gondii tissue cysts is a common practice. Infected felids can spread T. gondiioocysts in their environment and thus contaminate food, bedding, and water. In some zoo felids (Otocolobus manul), toxoplasmosis with a fatal outcome has been reported (Bartova 2014). Carnivores can also be infected by hunting some small prey species with free access to the zoo, such as small wild rodents and birds. Another source of infection might be the presence of feral cats in the zoo, which can spread oocysts in their feces to zoo enclosures. In our study, T. gondii was detected by PCR in tissues of four wild rodents and in one laboratory mouse that died. The laboratory 
mouse came from a specific pathogen-free breeding compound; the route of infection of this animal remains unknown. One possibility is food contaminated with sporulated T. gondii oocysts due to improper storage of prepared pellets.

Fatal toxoplasmosis was described in six tammar wallabies (Macropus eugenii) in the Budapest Zoo and Botanical Garden between 2006 and 2010 (Sos, 2012). Wallabies are known to be susceptible to T. gondii infection, and feral cats are suggested as the main source of the parasite in the zoo environment. In our study, a high prevalence of $T$. gondii was found in Camelids and Diprotodontia, which could be related to contamination of food such as hay or of substrate material in their enclosures, which is mostly sand. A high risk of contamination of this substrate with the feces of feral cats as well as difficulties in keeping stray cats outside the zoo (it is located in the city) increase the possibility of infection with T. gondii oocysts. New World Primates are highly susceptible to clinical toxoplasmosis, and the infection is often fatal with various pathological manifestations (Epiphanio, 2003). High prevalence was previously recorded in primates such as the red-faced spider monkey (Ateles paniscus) and tufted capuchin (Cebus apella) from a zoo in Brazil, at $67 \%$ (Minervino, 2010), and in a Barbary macaque (M. sylvanus), gorilla (Gorilla gorilla), chimpanzee (Pan troglodytes), and orangutan (Pongo pygmaeus) in the Czech Republic, at 45\% (Sedlak, 2006). In our study, T. gondiiantibodies were found in $25 \%$ of primates (chimpanzee, Pan troglodytes ). Ingestion of sporulated T. gondii oocysts in contaminated feed is presumed to be the main source of infection. Carefully washing vegetables and fruits as well as regularly cleaning the kitchen may reduce the risk of infection in this group of animals. Toxoplasmosis has been recorded in zoo birds; for example, in canaries and black-winged lories (Eos cyanogenia) (Weiss, 2011). In our study, antibodies to T. gondii were not found in any of the birds tested; however, two mute swans died and T. gondii was detected in their tissue by PCR. These samples were genotyped and characterized as type II, which is known to be highly predominant in humans and animals in Europe and North America (Costache, 2013; de Sousa, 2006). Water contaminated with T. gondii oocysts is one possible source of the infection in this case.

E. cuniculi is a very important parasite of rabbits throughout Europe (Jordan, 2006). This is in accordance with results from our study because we found the highest prevalence of E. cuniculi antibodies in Lagomorpha $(83 \%)$ in European rabbits (Oryctolagus cuniculus). Placentitis, premature birth, and perinatal death has been described in connection with E. cuniculi infection in an alpaca (Vicugna pacos ) (Webster, 2008). In our study, a high prevalence of E. cuniculi antibodies was found in Bovidae (81\%) and Camelidae (67\%). Antibodies to E. cuniculi were found in an alpaca (Vicugna pacos) and a guanaco (Lama guanicoe). One E. cuniculi -seropositive alpaca died, but the parasite was not detected by PCR in its tissue.

Clinical disease and positive isolation of E. cuniculi was reported in captive emperor tamarins (Saguinus imperator ) and cotton-top tamarins (Saguinus oedipus), which seem to be highly susceptible to infection (Guscetti 2003; Juan-Sales 2006). In our study, chimpanzees, lemurs, and gibbons were negative. Herbivores had a higher chance of being infected compared to carnivores, which could suggest the presence of $E$. cuniculi spores in the environment as a main source of infection. E. cuniculi infection in birds has no clinical importance, but some avian species could serve as reservoirs for these microsporidia (Hinney, 2016). In our study, antibodies toE. cuniculi were found in mute swans and helmeted guineafowls (Numida meleagris ) .

Chlamydia abortus and Coxiella burnetii are pathogens that are well known to cause abortions as well as various health problems in zoo animals (Lloyd, 2010). The negative results obtained in our study may be due to limited exposure, good preventive veterinary care, and suitable disinfection plans.

Zoos are institutions open to the public. A large variety of different animal species usually with a high density of animals, open enclosures, the presence of stray cats and wild rodents, and close contact with people are important factors for transmission of diseases, often with anthropo-zoonotic potential, which raises public health concerns. Therefore, monitoring transmissible diseases in zoo animals and understanding their dynamics is of great importance and is an inseparable part of preventive health care in zoological collections.

Financial support: The study was supported by internal grant of VFU Brno (FVHE/Literak/ITA2019). 


\section{Acknowledgments}

We thank the keepers working at the Ljubljana Zoo for their help with sample collection, Margita Přikrylová for sample examination, and Alexandra Valenčáková for optimalization of the PCR used for detection of $E$. cuniculi .

Conflict of Interes Statement: The authors do not have a conflict of interest.

Data Availability Statement: The data that support the findings of this study are available on request from the corresponding author. The data are not publicly available due to privacy or ethical restrictions.

Ethical Statement: The authors confirm that the ethical policies of the journal, as noted on the journal's author guidelines page, have been adhered to. No ethical approval was required. All samples have been collected as a secondary interest by zoo personal during clinical procedures, surgeries, annual health checkups.

\section{Author Bio}

Pavel Kvapil graduated from the Faculty of Veterinary Medicine at the University of Veterinary and Pharmaceutical Sciences, Brno in the Czech Republic in 2005. He started working as a veterinarian at the Ljubljana Zoo in Slovenia in 2008, and he became the head veterinarian in 2014. He is currently working on a dissertation, with a focus on infectious diseases in zoo animals and wild animals at the Department of Biology and Wildlife Diseases, Faculty of Veterinary Hygiene and Ecology at the University of Veterinary and Pharmaceutical Sciences, Brno.

\section{References}

Ajzenberg, D., Collinet, F., Mercier, A., Vignoles, P., \& Dardé, M. L. (2010). Genotyping of Toxoplasma gondii isolates with 15 microsatellite markers in a single multiplex PCR assay. Journal of Clinical Microbiology, 48, 4641-4645.

Bartova, E., Sedlak, K., Nagl, I., Vodicka, R., Racka, K., Slezakova, R., \& Ajzenberg, D. (2014). Genotyping of Toxoplasma gondiiisolated from Pallas's cats with fatal toxoplasmosis. Infectious and Parasitic Diseases of Animals, 5th International Scientific Conference, Košice, Slovakia.

Costache, C. A., Colosi, H. A., Blaga, L., Györke, A., Paştiu, A. I., Colosi, I. A., et al. (2013). First isolation and genetic characterization of a Toxoplasma gondii strain from a symptomatic human case of congenital toxoplasmosis in Romania. Parasite, 20, 11.

Cristina, N., Oury, B., Ambroise-Thomas, P., \& Santoro, F. (1991). Restriction-fragment-length polymorphisms among Toxoplasma gondiistrains. Parasitology Research,77, 266-268.

de Sousa, S., Ajzenberg, D., Canada, N., Freire, L., da Costa, J. M. C., Dardé, M. L., et al. (2006). Biologic and molecular characterization of Toxoplasma gondii isolates from pigs from Portugal. Veterinary Parasitology, 135, 133-136.

Epiphanio, S., Sinhorini, I. L., \& Catão-Dias J. L. (2003). Pathology of toxoplasmosis in captive new world primates. Journal of Comparative Pathology, 129(2-3), 196-204.

Guscetti, F., Mathis, A., Hatt, J. M., \& Deplazes, P. (2003). Overt fatal and chronic subclinical Encephalitozoon cuniculimicrosporidiosis in a colony of captive emperor tamarins (Saguinus imperator ). Journal of Medical Primatology, 32, 111-119.

Hinney, B., Sak, B., Joachim, A., \& Kváč, M. (2016). More than a rabbit's tale: Encephalitozoon spp. in wild mammals and birds. International Journal for Parasitology: Parasites and Wildlife, 5, 76-87.

Jordan, C. N., Zajac, A. M., \& Lindsay, D. S. (2006). Encephalitozoon cuniculi infection in rabbits. Compendium on Continuing Education for the Practising Veterinarian-North American Edition, 28(2), 108. 
Juan-Sallés, C., Garner, M. M., Didier, E. S., Serrato, S., Acevedo, L. D., Ramos-Vara, J. A., \& Paras, A. (2006). Disseminated encephalitozoonosis in captive, juvenile, cotton-top (Saguinus oedipus ) and neonatal emperor (Saguinus imperator ) tamarins in North America. Veterinary Pathology, 43, 438-446.

Lloyd, C., Stidworthy, M. F., \& Wernery, U. (2010). Coxiella burnetii abortion in captive dama gazelle (Gazella dama) in the United Arab Emirates. Journal of Zoo and Wildlife Medicine, 41, 83-89.

McNamara, T. (2007). The role of zoos in biosurveillance. International Zoo Yearbook, 41(1), 12-15.

Minervino, A. H. H., Soares, H. S., Barrêto-Júnior, R. A., Neves, K. A. L., de Jesus Pena, H. F., Ortolani, E. L., \& Gennari, S. M. (2010). Seroprevalence of Toxoplasma gondii antibodies in captive wild mammals and birds in Brazil. Journal of Zoo and Wildlife Medicine, 41, 572-574.

Muller, N., Zimmermann, V., Hentrich, B., \& Gottstein, B. (1996). Diagnosis of Neospora caninum and Toxoplasma gondiiinfection by PCR and DNA hybridisation immunoassy. Journal of Clinical Microbiology, $34,2850-2852$.

Sedlák, K., \& Bártová, E. (2006). Seroprevalences of antibodies toNeospora caninum and Toxoplasma gondii in zoo animals. Veterinary Parasitology, 136, 223-231.

Sós, E., Szigeti, A., Fok, É., Molnár, V., Erdélyi, K., Perge, E., \& Gál, J. (2012). Toxoplasmosis in tammar wallabies (Macropus eugenii ) in the Budapest Zoo and Botanical Garden (2006-2010). Acta Veterinaria Hungarica, 60, 361-370.

Statsoft, Inc. (2013). STATISTICA (data analysis software system), version 12. www.statsoft.com.

Valenčáková, A., Balent, P., Novotný, F., \& Čisláková, L. (2005). Application of specific primers in the diagnosis ofEncephalitozoon spp. Annals of Agricultural and Environmental Medicine, 12, 321-323.

Webster, J. D., Miller, M. A., \& Vemulapalli, R. (2008).Encephalitozoon cuniculi associated placentitis and perinatal death in an alpaca (Lama pacos ). Veterinary Pathology, 45, 255-258.

Weiss, L. M., \& Kim, K. (2011). Toxoplasma gondii: The Model Apicomplexan. Perspectives and methods . Cambridge, MA: Academic Press.

Address for correspondence: Pavel Kvapil, Ljubljana Zoo, Ljubljana, Slovenia, and University of Veterinary and Pharmaceutical Sciences, Brno, Faculty of Veterinary Hygiene and Ecology, Department of Biology and Wildlife Diseases, Brno, Czech Republic, E-mail:

\section{Hosted file}

tables - selected pathogenes-biosurveilance-TED.odt available at https://authorea.com/users/ 391681/articles/505720-biosurveillance-of-selected-pathogens-with-zoonotic-potential-ina-zoological-collection 